Military Technical College

Kobry El-Kobbah,

Cairo, Egypt

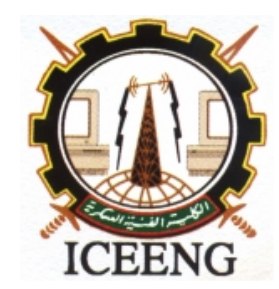

$7^{\text {th }}$ International Conference on Electrical Engineering ICEENG 2010

\title{
Building Knowledgebase for Distributed Resources' Projects
}

$$
\text { By }
$$

Mohamed H. El-Banhawy*

\section{Abstract:}

This paper discuss and propose roadmap to build the knowledgebase required for engineering, procurement, and construction management (EPCM) of Distributed resources (DR) projects. Technologies of Distributed Resources (DR) including renewable energy system have been surveyed and summarized in this paper. Roadmap for the implementation of the DR and Microgrid projects by an EPCM firm was proposed. It is foreseen that such system could be applied for Housing compounds, factories, and tourism villages.

\section{Keywords:}

Distributed Resource, Distributed Generation, Microgrid.

* Power Generation Engineering and Services Company (PGESCo) 


\section{Introduction:}

This paper discuss and propose methods to build the knowledgebase required for engineering, procurement, and construction management (EPCM) of Distributed resources (DR) projects.

DR is sought to be small renewable or non renewable power or energy generation plants built to supply small area power system or Microgrid and connected to the main Electrical Power System (EPS). It is essential that establishments planning for EPCM projects for DR should own knowledgebase for components of this system including classic and emerging technologies for: rotating prime movers running synchronous generators; or Wind Turbines with induction generators; or photovoltaic (PV) arrays, and Fuel Cell using ac/dc inverters.

This paper is limited to DR projects utilized for supplying power, energy, or heating to very small or Microgrid (MG) power system. The following clauses 2, 3, and 4 include survey of these technologies, whereas clause 5 includes necessary knowledgebase for EPCM projects. Clause 5 summarizes a proposed roadmap to build such knowledgebase.

\section{Distributed Resources $(\mathrm{DR})$ :}

DR technologies for generating power or energy for Microgrid could be one of the following ${ }^{(1)}$

- Rotating prime movers as: Reciprocating engines, combustion turbines, steam turbines (not normally used for DR and is not covered in this paper), wind turbines, and Microturbines.

- Non-Rotating prime movers as: Solar or PV arrays, Fuel cells, and energy storage systems. Non-rotating technologies produce dc current and need to connect to EPS through static inverters.

\section{Reciprocating Engines}

This is classic technology and could be either small four stroke high speed engines that use light diesel fuel, OR two strokes low speed engines that can be run on heavy fuel oil, or burning biomass or landfill gas. The later fuels are considered environment friendly and they are renewable energy source. Reciprocating engines for DR are available from many manufacturers in all sizes with proven service records.

\section{Combustion Turbines}

Gas or oil fired combustion turbines are based on classic technology with proven service 
experience. They have short delivery and installation time, however require expensive regular maintenance. Combustion turbines are available from a number of manufacturers all over the world.

\section{Microturbines}

This is a small high speed combustion turbine that is derived from aircraft auxiliary power system, or diesel engines turbochargers. They are available from number of manufacturers for DR in the range of $30 \mathrm{~kW}$ to $500 \mathrm{~kW}$.

\section{Wind Turbines $^{(0)}$}

Wind Turbine Generation (WTG) contribution to EPS is considered the fastest-growing energy sources worldwide, due to savings in fuel cost displacement and cleaner energy. However it requires special attention for planning its interconnection and operation systems. The integration of WTG is affected by the inability to forecast wind resource versus energy need.

One scenario of the European "TradeWind" project (exchange wind energy among European country) is planning to build $30 \mathrm{GW}$ of WTG, which represent about is $35 \%$ of total load by 2030.

Egypt has a major WTG projects, either completed or in process, however not DR projects. WTG is now available from a number of manufacturer (part of it can be manufacturer locally in Egypt). WTG normally use induction generators or double fed induction generators.

\section{PV Systems}

PV systems supply energy to the Microgrid through dc/ac inverters, when its renewable energy is available (sun light in this case). At night time, or when PV energy is not enough the Microgrid could be supplied back from the EPS or from energy stored in a Storage Battery, the later is applicable for remote areas.

The PV cells are connected in parallel and series to form glass encapsulated modules or arrays. The silicon crystal PV cells were developed in 1950 and its technology continues to advance increasing the energy production higher and higher, and decreasing its cost lower to earth. Countries such as Japan, Germany, and the Netherlands have implemented "solar roof" programs, which have resulted in the installation of hundreds of thousands of residential PV systems. These systems range from $50 \mathrm{~W}$ ac modules to a 2 MW roof over a Netherlands farmers, market. 
Egypt research in the PV field goes back to 1957 when a national program to develop renewable energy systems was started in National Research Center of Egypt. ${ }^{(4)}$ Many pilot projects, many of them were funded by International authorities, were implemented since then ${ }^{(3),(4)}$ including a power plant at Kureimat site however, no commercial application had taken place due the high cost of $\mathrm{PV}$ installed $\mathrm{kW}$ relative to other energy sources. It is foreseen that PV installation cost will go down in the very near future that will make it economical for commercial application.

PV is most suitable to DR as it can be installed near to the load, and its output is at its maximum at mid-day during the peak demand of the air conditioning system in a warm summer as in Egypt.

\section{Energy Storage Technologies}

During low load the energy can be used to charge an energy storage system, which can be regained during peak times. Pumped hydro is known and used by some utility. Large storage Batteries is another application that can be used for automatic and fast compensation of generation loss in this case it is connected to the EPS through special inverter/converter scheme.

\section{Fuel Cells ${ }^{(1)}$}

Although Fuel Cell was first developed in 1838, it was not put in use until 1960 when it is used by NASA to fuel Gemini and Apollo spacecraft. Fuel Cell requires Hydrogen for operation, and extracts it from hydrogen-reach sources such as gasoline, propane, and natural gas. Fuel is still under development to have proven applicable technology to be used for DR.

\section{Interconnection to EPS:}

The DR intended to supply small system or Microgrid and in the same time interconnect with the main EPS. A Microgrid is a new type of power system, which is formed by the interconnection of small, modular generation to low voltage distribution systems. Microgrids can be connected to the main power network or be operated autonomously. The interconnection system in this case includes several functions as:

- Synchronizing and paralleling,

- Power source transfer,

- Metering and Monitoring,

- Electrical protection, 
- SCADA and communication,

- DR control.

The above functions are normally available for large power plants, however there will be differences as the interconnection rules will be different based on the EPS requirement. During connection with the EPS, the energy might be flowing in both directions to or from the Microgrid. This will have different control schemes and logics for based on the type of DR electrical system.

\section{Knowledgebase:}

Building a Knowledgebase for all the above collected in a suitable form is an essential requirement for Engineering, Procurement, Construction Management (EPCM) firm to enter the market of DR and Microgrid.

Knowledgebase for DR projects at least include the state-of-the-art specifications and data sheets, information on the specialized manufacturer, cost and delivery periods of individual equipments. It is natural that such information will not be useful without having expert technical staff members on DR equipments.

\section{Roadmap:}

Several countries have developed standard and regulations to accommodate DR within its EPS. Although large renewable energy WTG and PV projects were implemented in Egypt by the Ministry of Electricity, the application of DR and Microgrid still in very small scale. It is proposed for the Egyptian EPCM firms to build its own knowledgebase and market their business to the local developers of housing compounds, factories, and tourism villages. The following is a proposed Roadmap to build such knowledgebase:

1- Firm to appoint a task-force to perform techno-economic analysis for the selection for the most promising technology for the DR and its interconnection with the EPS.

2- Collect information of applied projects from US, Europe and Japan Utilities. This step should be conducted in collaboration of Egyptian utilities.

3- Contact and visit manufacturers to have specifications, data sheets and hands-on experience on the most promising systems.

4- Prepare standard designs for DR modules of different sizes that are suitable the application foreseen in Egypt.

5- Start aggressive market survey and business development for DR and Microgrid.

6- Awareness has to be increased, since there is still a lack of understanding about these 
technologies among the general public. Many potential customers, especially residential users, are unfamiliar with the option of on-site power generation.

7- Incentive programs to encourage the immediate use of commercially available cleanest technologies.

\section{Conclusions:}

Technologies of Distributed Resources (DR) including renewable energy system have been surveyed and summarized in this paper. In Clause 5 a Roadmap for the implementation of the DR and Microgrid projects by an EPCM firm was proposed. It is foreseen that such system could be applied for Housing compounds, factories, and tourism villages.

\section{References:}

1. IEEE Std. 1547.2-2008, Application Guide for IEEE1547, IEEE standard for Interconnection Distributed Resources with Electric Power System.

2. D. Corbus, D. Lew, G. Jordan, F. Van Hull, J. Manobianco, and B. Zavadil, "Up with Wind," IEEE Power and Energy Magazine, Volume 7, Number 6, Nov/Dec 2009.

3. Fadia M. A. Ghali, "Photovoltaic Small-Scale Wastewater Treatment Project for Rural and New-Cultivated Areas in Egypt", World Academy of Science, Engineering and Technology 53, 2009.

4. S.H. El-Hefnawi, "Photovoltaic Applications and Research in Egypt and Marketability of PV in Developing Countries", ISESCO Science and Technology, Volume 1, May 2005 (23-29). 